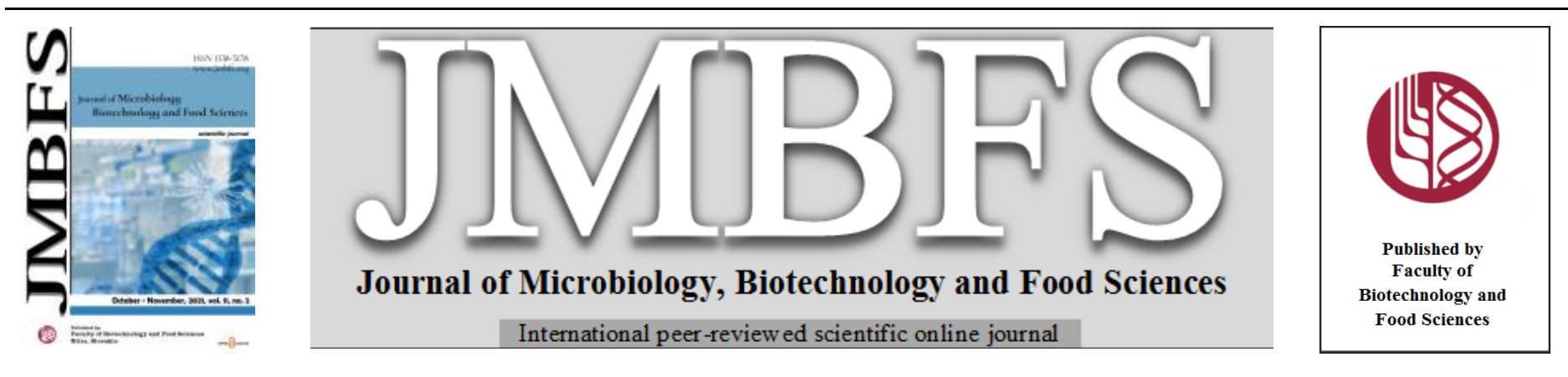

\title{
ISOLATION AND IDENTIFICATION OF CHOLESTEROL OXIDASE PRODUCING ACTINOMYCETES FROM EGYPTIAN SOIL FOR A LARGE SCALE FERMENTATION IN SUBMERGED CULTURES
}

\author{
Nayera A.M. Abdelwahed ${ }^{1 *}$, Hassan M. Awad ${ }^{1}$, Ismail G. Said $^{1}$, Amira A. Gamal $^{1}$, Elsayed A. Elsayed ${ }^{1,2}$, Amira A. Hassan $^{l}$
}

Address(es):

${ }^{1}$ Chemistry of Natural and Microbial Products Department, Pharmaceutical and Drug Industries Research Division, National Research Centre, 33 El Bohouth st.(former El Tahrir st.), P.O 12622, Dokki, Giza, Egypt.

${ }^{2}$ Bioproducts Research Chair, Zoology Department, College of Science, King Saud University, Riyadh 11451, Saudi Arabia.

*Corresponding author: : niarawahed@yahoo.com

https://doi.org/10.15414/jmbfs.4152

\section{ARTICLE INFO}

Received 31. 12. 2020

Revised 4. 5. 2021

Accepted 18. 5. 2021

Published 1. 10. 2021

Regular article

OPEN $\partial_{\text {ACCESS }}$

\section{ABSTRACT}

Isolation and identification of new microbial isolates capable of producing cholesterol oxidase enzyme (CHO) is of great potential in the field of biotechnology of industrial enzymes. Four producing strains of actinomycetes were isolated from Egyptian soils demonstrated high activity in cholesterol degradation compared to the other isolates. Based on different standard morphological, biochemical as well as molecular techniques using $16 \mathrm{~S}$ rRNA sequencing, these actinomycetes were identified as Streptomyces sp. strain NHIA_CH3 MK680299, Streptomyces sp. strain NHIA_CH5 MK680300, Streptomyces griseus strain NHIA_CH6 MK680301 and Streptomyces drozdowiczii strain NHIA_CH10 MK680302. In order to optimize the CHO enzyme activity, different fermentation media were tested in submerged cultures at shake flask level. Maximum activity $(23.7 \mathrm{U} / \mathrm{mL})$ was observed in culture of Streptomyces sp. strain NHIA_CH5 which was scaled up to the 5L volume of the stirred tank bioreactor. Results of the batch fermentation showed an earlier production of $\mathrm{CHO}$ enzyme with $4 \%$ increase in activity compared to that obtained from shake flask cultures indicated that Streptomyces sp. strain NHIA_CH5 could be a potential source of CHO enzyme for commercial purpose.

Keywords: isolation, Streptomyces sp., cholesterol oxidase, optimization, scale up

\section{INTRODUCTION}

Cholesterol oxidase $(\mathrm{CHO})$ is a flavoenzyme, oxidizes cholesterol and converts 5 cholesten-3 $\beta$-ol into 4 cholesten-3-one. This reaction is a first step in the microbial degradation of cholesterol and its derivatives (Saranya et al., 2014). $\mathrm{CHO}$ is an important precursor for the synthesis of hormones and steroidal drug intermediate (Fazaeli et al., 2018) and has a broad range of applications, i.e. cholesterol determination in food and medicine, cholesterol biotransformation into valuable products, preparation of food stuffs and inhibition of cotton weevil growth. Furthermore, cholesterol oxidases were involved in the appearance of Alzheimer's disease, tuberculosis and HIV (Srivastava et al., 2015). Hence, researches on microbial $\mathrm{CHO}$ have received much attention in recent years. Microbial conversions of cholesterol are more regio- and stereo-selective when compared to chemical reactions and have been used for a long time in the production of pharmaceutical products (Saranya et al., 2014). Studies have reported extracellular $\mathrm{CHO}$ production in shake flasks from microorganisms, e.g., Pseudomonas sp., Arthrobacter sp. Rhodococcus equi, Brevibacterium sterolicum, Mycobacterium sp., as well as some Streptomyces strains, i.e $S$. violascens (Srivastava et al., 2018a). Streptomyces are Gram-positive soil microorganisms capable of producing a variety of industrially important enzymes. Furthermore, compared to other producers, Streptomyces-produced $\mathrm{CHO}$ are generally more stable, have longer storage times, and are cost-effective (Elsayed \& Abdelwahed, 2020). Production of $\mathrm{CHO}$ in submerged fermentation is greatly influenced by medium composition and strain capacity. This could minimize the cost for overall production process. Different parameters such as $\mathrm{pH}$, medium composition, temperature, aeration, agitation and controlling of the dissolved oxygen (DO) was achieved previously during a scale-up study for CHO production (Thiry \& Cingolani , 2002). The present study was aimed to isolate the most potent cholesterol degrading actinomycete strains to evaluate maximum ability for $\mathrm{CHO}$ production in the selected suitable medium containing cholesterol as inducer in submerged cultures at shake flask level followed by a large-scale bioprocess in $5 \mathrm{~L}$ bioreactor to achieve more production yield and help in providing information to apply in future industrial process scale-up.

\section{MATERIALS AND METHODS}

\section{Isolation of actinomycetes}

Actinomycetes screened in this study were isolated from various soil samples collected from different localities in Egypt. One hundred grams of soil samples were taken in sterile Petri dishes individually and placed in hot air oven at $70{ }^{\circ} \mathrm{C}$ for $10 \mathrm{~min}$. The treated samples were serially diluted and plated on starch-nitrate agar medium of the following composition (g/L): Starch 20; $\mathrm{KNO}_{3} 2 ; \mathrm{K}_{2} \mathrm{HPO}_{4} 1$; $\mathrm{MgSO}_{4} .7 \mathrm{H}_{2} \mathrm{O} 0.5$; agar 20 and distilled water up to $1 \mathrm{~L}$ [supplement with Nalidixic acid $(10 \mu \mathrm{g} / \mathrm{mL})$ and Amphotericin B $(20 \mu \mathrm{g} / \mathrm{mL})]$ using the spread plate technique then the plates were incubated at $30{ }^{\circ} \mathrm{C}$ for $8-10$ days. Morphologically distinct actinomycetes isolates were picked up, streaked, cultivated a number of times on starch-nitrate agar medium plates, and then incubated at $30^{\circ} \mathrm{C}$ for $8-10$ days to check its purity. The pure actinomycete isolates were maintained on starch-nitrate agar medium slants. For long-term storage, the cultures were preserved in $20 \%(\mathrm{v} / \mathrm{v})$ glycerol at $-80^{\circ} \mathrm{C}$ (Shepherd $\boldsymbol{e t}$ al., 2010).

\section{Screening for CHO producing organisms}

For screening of $\mathrm{CHO}$ enzyme producing actinomycetes, colonies were selected on suitable indicator agar plate containing $(\mathrm{g} / \mathrm{L})$ : 2 cholesterol, 1.0 Triton X-100, 0.1 O-dianisidine $1000 \mathrm{U} / \mathrm{L}$ peroxidase and 20 agar. Plates were incubated for 4 days at $30^{\circ} \mathrm{C}$. Cholesterol penetrates into actinomycete cells where it can be converted into hydrogen peroxide by $\mathrm{CHO}$. Reagents that exist in the medium react with hydrogen peroxide to form azo compound which turns the color of the medium to intense brown color (Srivastava et al., 2018). These isolates were maintained on slopes containing starch-nitrate agar medium. The isolates were stored as spore suspensions in $20 \%(\mathrm{v} / \mathrm{v})$ glycerol at $-80{ }^{\circ} \mathrm{C}$ for subsequent investigation.

Cultural, morphological and biochemical analysis 
were analyzed for cultural characteristics which described the growth, color of the aerial mass, soluble pigment and the substrate mycelium of the strain on different ISP media observed by naked eye. These characteristics of actinomycete isolates were observed in mature cultures grown on various media on the $7^{\text {th }}$, the $14^{\text {th }}$, and the $21^{\text {st }}$ day followed the guidelines adopted by the International Streptomyces Project (ISP) (Shirling \& Gottlieb, 1966). both spore chains and spore surface of the isolated strain were determined to discover the morphological properties of strains by a light microscope (Olympus CX41 optical microscope model LC20, GMBH, Münster, Germany) with digital camera output connected to a computer monitor. This was done using the cover slip technique as described by Shirling \& Gottlieb ( 1966). The spore surface of these isolated strains from the culture on 21 days of incubation was observed under transmission electron microscope (TEM) Zeiss EM 10 (Zeiss, Oberkochen, Germany). These characters and photos of the Streptomyces isolates were compared to the similar Streptomyces species in Bergey's Manual of Determinative Bacteriology Ninth edition (Cross, 1989). Carbon utilization was determined on plates containing ISP basal medium. Separately-sterilized carbon sources were added to a final concentration of $1.0 \%$. The plates were incubated at $30^{\circ} \mathrm{C}$ and the growth using glucose as positive control was noticed after 7, 14 and 21 days (Ismail et al., 2017; Awad \& Germoush, 2017).

\section{Molecular identification and phylogenetic analysis of the isolated strains}

Strains were grown on a slant of the actinomycete isolation agar medium for 7-10 days at $30^{\circ} \mathrm{C}$. Two $\mathrm{ml}$ of spore suspension were inoculated in the ISP 2 broth medium and incubated on incubator shaker Innova 4080 (New Brunswick, NJ, USA) at $200 \mathrm{rpm}$ and $30^{\circ} \mathrm{C}$ for $24 \mathrm{~h}$ to form pellets of vegetative cells. Total genomic DNA extraction and purification were carried out according to the method of Lee et al. (1989). The polymerase chain reaction (PCR) amplification and sequencing were carried out as described by Rintala et al., (2001). The nucleotide sequences of the 16S rRNA gene of the isolated strains have been deposited in NCBI database of the GenBank under different accession numbers. Phylogenic data were obtained by aligning the nucleotides of different $16 \mathrm{~S}$ rRNA retrieved from the Basic Local Alignment Search Tool (BLAST) algorithm available through the National Center for Biotechnology Information (NCBI) website (http://www.ncbi.nlm. nih.gov), using the CLUSTAL W program version 1.8 with standard parameters.

\section{Effect of different media for the production of CHO}

Different production liquid media described before from literatures to support $\mathrm{CHO}$ production representing a broad range of nutrient sources were investigated for the primary evaluation of medium optimization process. Fifty $\mathrm{mL}$ starchnitrate broth medium as mentioned above was inoculated with a loop full from slant culture to prepare the seed culture, then incubated at $30{ }^{\circ} \mathrm{C}$ for $48 \mathrm{~h}$ with shaking at $200 \mathrm{rpm}$. A two percent (v/v) from the seed culture was transferred to each $250 \mathrm{ml}$ Erlenmeyer flask containing $50 \mathrm{~mL}$ of the production media. The screening production media that were inoculated and incubated in an orbital shaker at $200 \mathrm{rpm}$ and $30^{\circ} \mathrm{C}$ for 5 days composed of $(\mathrm{g} / \mathrm{L})$ were as follow:

\begin{tabular}{|c|c|c|}
\hline $\begin{array}{l}\text { Medium } \\
\text { No. }\end{array}$ & Composition (g/L) & Reference \\
\hline 1 & $\begin{array}{l}\text { Glucose, } 4 ; \text { malt extract, } 10 ; \text { yeast } \\
\text { extract, } 4 ; \mathrm{CaCO}_{3 .} 2\end{array}$ & (Niwas et al., 2013) \\
\hline 2 & $\begin{array}{l}\text { Malt extract, 2; yeast extract, } 4 ; \\
\text { glucose, } 15 ; \text { peptone, } 5 ; \mathrm{MgSO}_{4} .7 \mathrm{H}_{2} \mathrm{O} \text {, } \\
0.5 ; \mathrm{K}_{2} \mathrm{HPO}_{4}, 1 ; \mathrm{NaCl}, 0.5\end{array}$ & (Niwas et al., 2013) \\
\hline 3 & $\begin{array}{l}\text { Soluble starch,10; peptone, } 6 ; \text { glucose, } \\
\text { 10; yeast extract, } 5 ; \mathrm{MgSO}_{4} .7 \mathrm{H}_{2} \mathrm{O}, 0.5 ; \\
\mathrm{K}_{2} \mathrm{HPO}_{4}, 1 ; \mathrm{NaCl}, 0.5\end{array}$ & (Tabatabaei et al., 2001) \\
\hline 4 & $\begin{array}{l}\text { Soluble starch, } 15 ; \text { malt extract, } 2 ; \text { yeast } \\
\text { extract, } 4 \text { peptone, } 0.5 ; \mathrm{MgSO}_{4} \cdot 7 \mathrm{H}_{2} \mathrm{O} \text {, } \\
0.5 ; \mathrm{K}_{2} \mathrm{HPO}_{4}, 1 ; \mathrm{NaCl}, 0.5\end{array}$ & (Varma et al., 2003) \\
\hline 5 & $\begin{array}{llll}\text { Soluble } & \text { starch, } 10 ; & \text { peptone, } & 30 ; \\
\text { glucose, } 10 ; & \text { beef extract, } & 30 ; \\
\mathrm{MgSO}_{4} \cdot 7 \mathrm{H}_{2} \mathrm{O}, 1 ; \mathrm{NaCl}, 7.5\end{array}$ & (Kajiya et al., 1991) \\
\hline 6 & $\begin{array}{l}\left(\mathrm{NH}_{4}\right)_{2} \mathrm{SO}_{4}, 2 ; \text { glycerol, } 5 ; \mathrm{K}_{2} \mathrm{HPO}_{4}, 2 ; \\
\mathrm{MgSO}_{4} .7 \mathrm{H}_{2} \mathrm{O}, 0.2 \text { and peptone, } 2\end{array}$ & (Richmond, 1973) \\
\hline
\end{tabular}

The fermentation profile was studied by harvesting triplicate flasks at intervals of $24 \mathrm{~h}$. Supernatants of the fermented cultures were obtained by centrifugation of the media at 5,000 rpm for $10 \mathrm{~min}$ at $4^{\circ} \mathrm{C}$ for protein determination and enzyme assay.

\section{Up scaling of CHO production in 5L stirred tank bioreactor}

Cultivations in bioreactor level were carried out using 5L-stirred tank bioreactor (Bioflo 310, New Brunswick Scientific, New Brunswick, NJ, USA), with a working volume of $3 \mathrm{~L}$. Filtered sterile air was introduced to the bioreactor at an aeration rate of $0.5 \mathrm{v} / \mathrm{v} / \mathrm{min}$. The concentrations of dissolved oxygen were measured using polarographic electrode (Ingold, Switzerland). The $\mathrm{pH}$ of the bioreactor cultivations was initially adjusted at 7.0 using standard $\mathrm{NaOH} / \mathrm{HCl}$ solutions, and was kept uncontrolled throughout the bioreactor run. Agitation was performed using a two 6-bladed Rushton turbine impellers (di (impeller diameter $)=75 \mathrm{~mm}$; $\mathrm{dt}($ tank diameter $)=215 \mathrm{~mm}$; di $/ \mathrm{dt}=0.35)$ at $300 \mathrm{rpm}$. If applicable, foam was suppressed using silicon antifoam reagent (Fluka, Switzerland). Temperature was adjusted at $30^{\circ} \mathrm{C}$. All the samples were analyzed for three times and the average mean of the data are represented.

\section{Determination of $\mathrm{CHO}$ activity}

The enzymatic activity assay of $\mathrm{CHO}$ is based on the conversion of cholesterol to 4-cholestene-3-one. The assay was performed by following the method of Allain et al. (1974). One unit of $\mathrm{CHO}$ has been defined as the quantity of the enzyme required to produce $1.0 \mu \mathrm{mol}$ of 4 -cholesten-3-one per min at $\mathrm{pH} 7.0$ and $37^{\circ} \mathrm{C}$. The concentration of the protein/enzyme was measured by the method of Lowry et al. (1951) using bovine serum albumin (BSA) as a standard.

\section{RESULTS AND DISCUSSION}

\section{Actinomycetes isolation and screening for $\mathrm{CHO}$ activity}

It is of great importance to obtain the required isolate in a pure culture to ease the following optimization and production processes. Generally, $\mathrm{CHO}$ indicator agar method is used to confirm the ability of the isolated strain to produce $\mathrm{CHO}$. During the screening, out of ten actinomycete isolates from soil samples were collected from various areas in Egypt, four showed promising activities to degrade cholesterol as noticed by the intense brown color on indicator agar plates having cholesterol as the only $\mathrm{C}$-source. Accordingly, cholesterol was converted into 4cholesten-3-one and $\mathrm{H}_{2} \mathrm{O}_{2}$ to form azo-compound (Schiff 's base) as represented in figure 1 . The 4 potent isolates were selected and subjected to identification (Nagasawa et al., 1969; Srivastava et al., 2018).

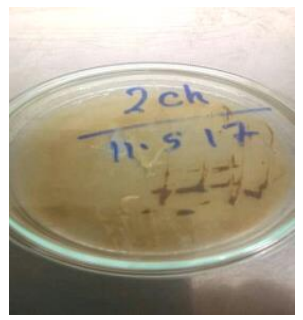

Figure 1 Formation of AZO component because of $\mathrm{CHO}$ production by one of the isolated actinomycete

\section{Cultural and microscopic characteristics of $\mathrm{CHO}$ producers isolates}

In this study, the identification of the four $\mathrm{CHO}$ enzyme producing isolates coded as NRC-CHO 3, NRC-CHO 5, NRC-CHO 6 and NRC-CHO 10 were obtained through colony morphology observation on starch-nitrate agar medium . Colonies are dry, compact, chalky-like, heaped, folded, slow growing, aerobic with aerial and substrate mycelia of different colors with an earthy odor. The isolated strains were able to grow and spread on ISP medium including both defined and undefined components. Furthermore, all selected strains grew moderately to heavily on ISP1, ISP2, ISP3, ISP4, ISP5, ISP6 and ISP7. It was observed that the abundance and the color of aerial mycelium depended on the medium composition and the age of the culture (Table 1). 
Table 1 Cultural characteristics of isolate coded NRC-CHO 3, NRC-CHO 5, NRC-CHO 6 and NRC-CHO 10 in different media

\begin{tabular}{|c|c|c|c|c|c|}
\hline \multirow{2}{*}{\multicolumn{2}{|c|}{ Medium }} & \multirow[b]{2}{*}{ Growth } & \multicolumn{3}{|l|}{ Color of } \\
\hline & & & $\begin{array}{l}\text { Aerial } \\
\text { mycelium }\end{array}$ & $\begin{array}{l}\text { Substrate } \\
\text { mycelium }\end{array}$ & $\begin{array}{l}\text { Diffusible } \\
\text { pigments }\end{array}$ \\
\hline \multicolumn{6}{|c|}{ Isolate NRC-CHO 3} \\
\hline 1 & Tryptone yeast extract broth (ISP 1) & Weak & Gray & Beige & None \\
\hline 2 & Yeast -malt extract agar (ISP 2) & Abundant & Gray & Light Brown & None \\
\hline 3 & Oat meal agar (ISP 3) & Abundant & Gray & Dark Beige & Beige \\
\hline 4 & Inorganic-trace salt- starch agar (ISP4) & Abundant & Gray & Brown & None \\
\hline 5 & Glycerol asparagine agar (ISP 5) & Abundant & Gray & Beige & None \\
\hline 6 & Peptone yeast extract iron agar (ISP 6) & Abundant & Gray & Gray & None \\
\hline 7 & Tyrosine agar (ISP 7) & Abundant & Gray & Beige & None \\
\hline 8 & Nutrient agar & Abundant & Gray & Brown & None \\
\hline 9 & Czapek's agar & Moderate & Gray & Beige & None \\
\hline \multicolumn{6}{|c|}{ Isolate NRC-CHO 5} \\
\hline 1 & Tryptone yeast extract broth (ISP 1) & Abundant & Light Beige & Beige & None \\
\hline 2 & Yeast -malt extract agar (ISP 2) & Abundant & Gray & Brown & None \\
\hline 3 & Oat meal agar(ISP 3) & Abundant & Gray & Beige & None \\
\hline 4 & Inorganic-trace salt- starch agar (ISP4) & Abundant & Gray & Brown Beige & None \\
\hline 5 & Glycerol asparagine agar (ISP 5) & Abundant & Gray & Beige & None \\
\hline 6 & Peptone yeast extract iron agar (ISP 6) & Abundant & Gray & Gray & None \\
\hline 7 & Tyrosine agar (ISP 7) & Abundant & Light Gray & Beige & None \\
\hline 8 & Nutrient agar & Abundant & Gray & Light Brown & None \\
\hline 9 & Czapek's agar & Abundant & Gray & Light Gray & None \\
\hline \multicolumn{6}{|c|}{ Isolate NRC-CHO 6} \\
\hline 1 & Tryptone yeast extract broth (ISP 1) & Abundant & Beige gray & Beige & None \\
\hline 2 & Yeast -malt extract agar (ISP 2) & Abundant & Gray & Light Brown & None \\
\hline 3 & Oat meal agar (ISP 3) & Abundant & Gray & Beige & None \\
\hline 4 & Inorganic-trace salt- starch agar (ISP4) & Abundant & Gray & Light Brown & None \\
\hline 5 & Glycerol asparagine agar (ISP 5) & Abundant & Light gray & Beige & None \\
\hline 6 & Peptone yeast extract iron agar (ISP 6) & Abundant & Gray & Beige & None \\
\hline 7 & Tyrosine agar (ISP 7) & Moderate & Light Gray & Light Beige & None \\
\hline 8 & Nutrient agar & Abundant & Gray & Light Brown & Light Yellow \\
\hline 9 & Czapek's agar & Abundant & Gray & Beige & None \\
\hline \multicolumn{6}{|c|}{ Isolate NRC-CHO 10} \\
\hline 1 & Tryptone yeast extract broth (ISP 1) & Abundant & Light Gray & Beige & None \\
\hline 2 & Yeast -malt extract agar (ISP 2) & Abundant & Gray & Brown & None \\
\hline 3 & Oat meal agar(ISP 3) & Abundant & Gray & Beige & None \\
\hline 4 & Inorganic-trace salt- starch agar (ISP4) & Abundant & Gray & Dark Brown & None \\
\hline 5 & Glycerol asparagine agar (ISP 5) & Abundant & Gray & Beige & None \\
\hline 6 & Peptone yeast extract iron agar (ISP 6) & Moderate & Gray & Beige & None \\
\hline 7 & Tyrosine agar (ISP 7) & Abundant & Gray & Beige & None \\
\hline 8 & Nutrient agar & Abundant & Gray & Brown & None \\
\hline 9 & Czapek's agar & Abundant & Gray & Brown & None \\
\hline
\end{tabular}

The actinomycete isolates vegetative hyphae were found to be branched and not fragmented. The characterization of these strains depended on the color of different mycelia, pigments, as well as spore form and surface. Under microscope, spore chain architecture changed according to strain type. These isolates were examined with light microscopy (100× magnification), on the ISP-2 to ISP-5, showed the spiral nature of the spore hyphae chains $(\mathrm{S})$ as in isolate NRC-CHO3 and NRC-CHO6 (Fig. 2a,c). While, the rectus-flexibilis (RF) was observed in isolates NRC-CHO5 and NRC-CHO10 (Fig. 2b,d). The spore surface of the selected isolates NRC-CHO3 was spiny (Fig.2e) and smooth spore surface was observed in NRC-CHO5, NRC-CHO6 and NRC-CHO10 (Fig. 2f, g, h). Furthermore, Salim et al. (2017) observed similar hyphae and colony structures for their isolated strains. Colonies formed long spore chains with more than ten spores/ chain. We suggested that the isolated strains belong to the genus Streptomyces by comparing their properties and features with those reported for known species of actinomycetes as in Bergey's manual of systematic bacteriology (Whitman et al., 1998). Further confirmation was obtained by studying their acid-fastness, Gram-staining pattern, where all 4 isolates showed negative acidfastness and positive Gram-staining (Taddei et al., 2006).
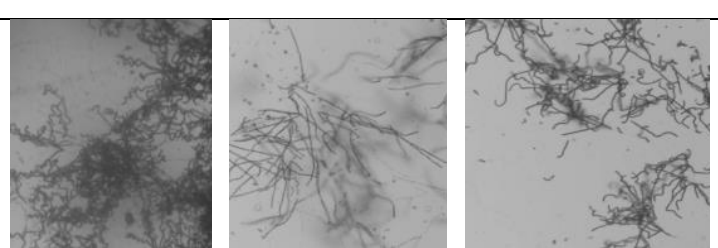

a) $\mathrm{NRC}-\mathrm{CHO} 3$
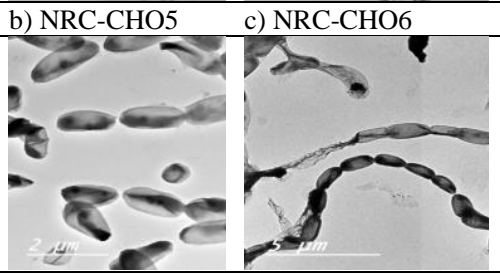

d) $\mathrm{NRC}-\mathrm{CHO} 10$
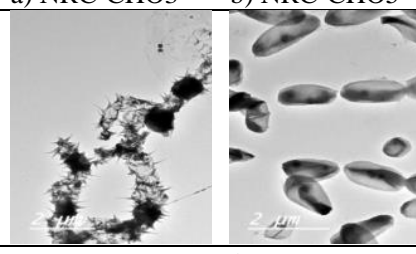

f) NRC-CHO5

g) NRC-CHO6

Figure 2 Micro-morphology of aerial hyphae and spore chain structure: a, c, d) spiral type, b) rectus flexible (RF) using light microscope 100x magnification. Spore surface: e) spiny as in isolate $\mathrm{NRC}-\mathrm{CHO} 3, \mathrm{f}, \mathrm{g}, \mathrm{h}$ ) smooth as in isolates NRC-CHO5, NRC-CHO6 and NRC-CHO10 $(\times 40.000)$ after 14 days of the incubation on Bennett's agar medium at $30^{\circ} \mathrm{C}$.

For the biochemical studies 9 tests were considered as a confirmatory identification to genus was achieved according to the work of Shirling \& Gottlieb (1966). Isolates were able to utilize most of the carbon sources with different degree based on the medium composition. The results were presented in table 2 . 
Table 2 Sugars utilization of isolates coded NRC-CHO3, NRC-CHO5, NRC-CHO6 and NRC-CHO10 Sugars utilization

\begin{tabular}{lcccc}
\multicolumn{1}{l}{ Sugars utilization } & Isolate NRC-CHO3 & Isolate NRC-CHO 5 & Isolate NRC-CHO 6 & Isolate NRC-CHO10 \\
\hline No carbon & - & - & + & + \\
\hline D-glucose & + & + & + & + \\
\hline D-xylose & +++ & +++ & +++ & ++ \\
\hline L-arabinose & ++ & +++ & + & + \\
\hline D-fructose & ++ & +++ & +++ & ++ \\
\hline Raffinose & +++ & +++ & +++ & ++ \\
\hline D-Manittol & +++ & +++ & +++ & + \\
\hline Meso- & +++ & ++ & +++ & ++ \\
\hline Salicin & +++ & ++ & ++ & ++ \\
\hline Sucrose & + & & & + \\
\hline
\end{tabular}

\section{Molecular Identification and Phylogenetic}

Molecular identification techniques are usually applied for their efficiency and rapidity (Boudemagh et al., 2005). Accordingly, 16S rRNA sequences were analyzed to confirm the identity of the isolated strains (Fig. 3). Results showed that the four isolated strains NRC-CHO3, NRC-CHO5, NRC-CHO6 and NRCCHO10 with nucleotide sequence $841 \mathrm{bp} ; 1133 \mathrm{bp} ; 1281 \mathrm{bp}$ and $735 \mathrm{bp}$ respectively were subjected to match with the 16S rRNA reported gene sequences in the gene bank database. The BLAST analysis clearly assigned the isolates to the Streptomyces genus, with $98 \%$ similarity and the isolate NRC-CHO 3 was assigned the nomenclature of Streptomyces sp. strain NHIA CH3 and its nucleotides were deposited at the GenBank under the accession number of (MK680299). Simirarly NRC-CHO5, NRC-CHO6 and NRC-CHO10 were assigned the nomenclature of Streptomyces sp. strain NHIA_CH5 (MK680300), Streptomyces griseus strain NHIA_CH6 (MK680301) and Streptomyces drozdowiczii strain NHIA CH10 (MK680302). Maleki et al. (2013) reported that $16 \mathrm{~S}$ rRNA identification is simpler and more efficient in identification of new Streptomyces strains. It is well reported that Streptomyces species usually constitute higher percentages of total actinomycete strains responsible for different bioactivities as well as industrial enzymes (Singh et al., 2016).

\section{Media selection for production optimization}

The selection of a suitable production medium is an important prerequisite for fermentative production of CHO. Cultivation medium provides generally growing cells with required energy sources and nutrients, which are then integrated within different cellular metabolic pathways (Singh et al., 2017). In the present study, six different fermentation media described previously for $\mathrm{CHO}$ production were tested. It has been previously shown that $\mathrm{CHO}$ production by Streptomyces is strain-dependent (Yamada et al., 2019). Here, screening of different production media with the four potent isolated strains was carried out. Figure 4 represents the effect of using different cultivation media on CHO levels over different incubation periods. It can be noticed that enzyme activity was increased linearly from 24 to $96 \mathrm{~h}$ and thereafter remained more or less constant in all culture media under test. Generally, the highest enzyme production was obtained after $96 \mathrm{~h}$ for the selected potent isolates. Medium 6 was found to be the most suitable for the production of CHO by Streptomyces sp. strain NHIA_CH3 and Streptomyces drozdowiczii strain NHIA_CH10 recorded the highest activity of 14.9 and $10.876 \mathrm{U} / \mathrm{mL}$ respectively whereas Streptomyces griseus strain NHIA_CH6 showed the highest activity of enzyme attained $12.54 \mathrm{U} / \mathrm{mL}$ in medium 1. In case of Streptomyces sp. strain NHIA_CH5, the present investigation revealed that, the highest $\mathrm{CHO}$ enzyme activity of $23.7 \mathrm{U} / \mathrm{mL}$ was achieved in culture media 5. Complex nutrients, i.e. yeast extract, cholesterol, potato starch, etc., were found to enhance $\mathrm{CHO}$ production (Yazdi et al., 2001). Moreover, Chauhan et al. (2009) reported that all organic nitrogen sources gave promising results whereas inorganic nitrogen sources supported very low biomass and CHO production. This is mainly due to the presence of different essential amino acids and growth factors in yeast extract, which enhances cellular performance, metabolism and CHO production consequently. In contrast, Yehia et al. (2015) found that inorganic $\mathrm{N}$-sources, e.g. $\mathrm{NaNO}_{3}$ and $\mathrm{NH}_{4} \mathrm{NO}_{3}, \mathrm{C}$-sources e.g. glycerol and xylose are the most suitable nutrients for $\mathrm{CHO}$ production by Pseudonocardia compacta S-39. Furthermore, Collins et al. (2013) used glycerol for higher biomass and CHO production by E. coli BL21 (DE3). However, cholesterol can also be consumed by the $\mathrm{CHO}$ producing microbe for energy and carbon sources (Arima et al., 1969). In this study, the optimum media obtained from shake-flask experiments using Streptomyces sp. strain NHIA_CH5 gave the highest activity compared to the other potent isolate under investigation, subsequently validation in $3 \mathrm{~L}$ working volume bench top bioreactor was investigated.
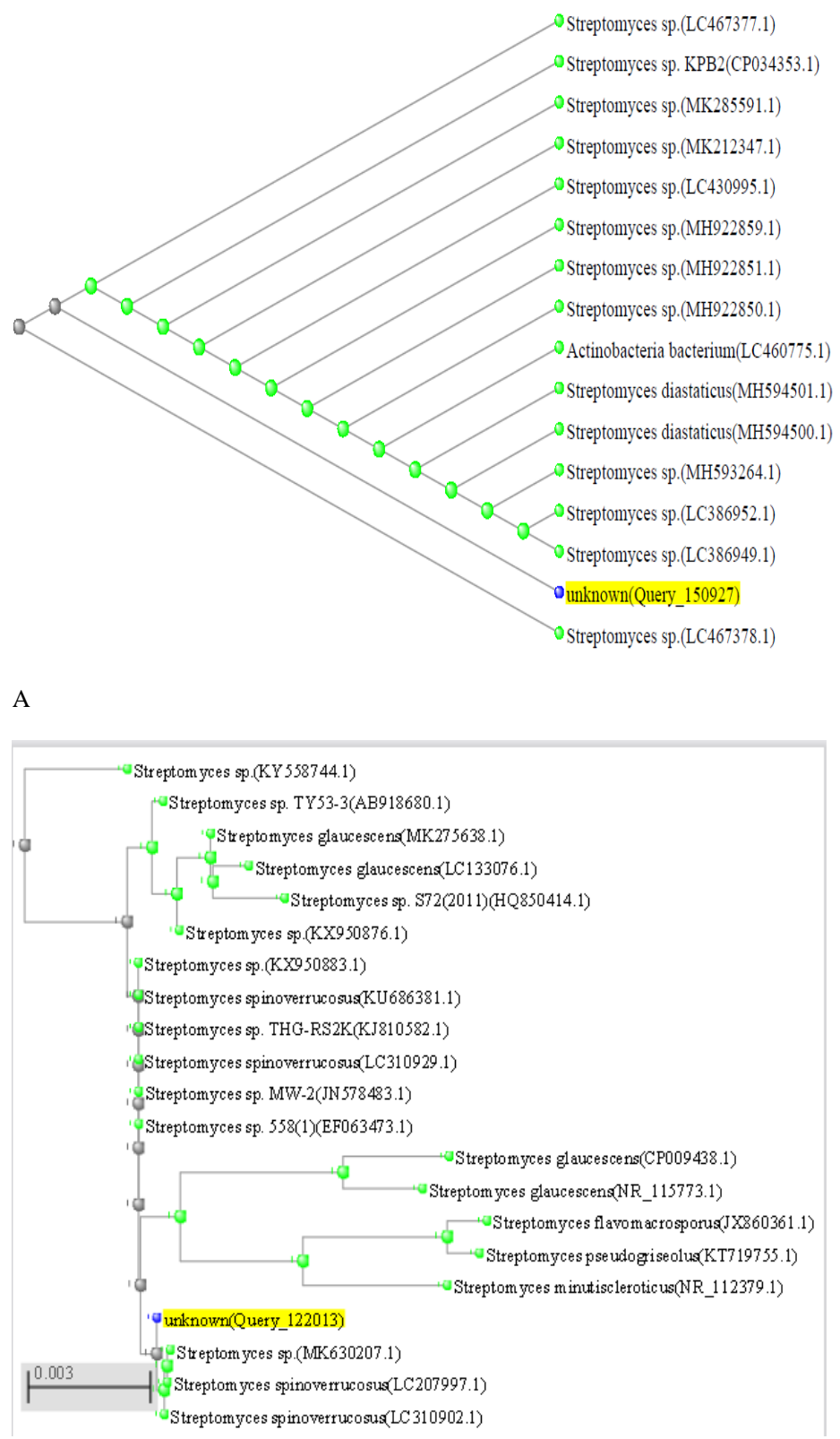

B 


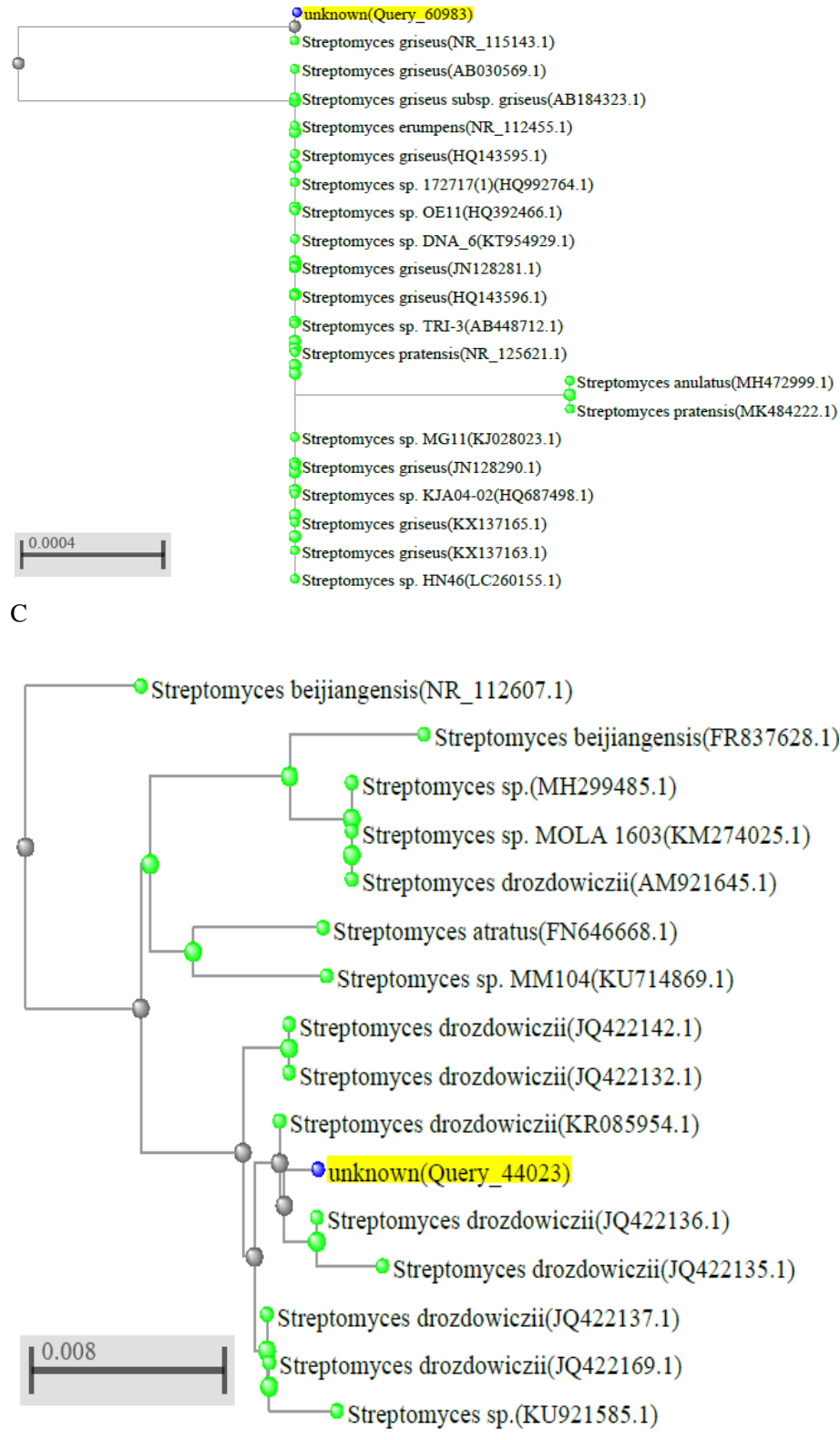

$\mathrm{D}$

Figure 3 Phylogenic tree of the 16S rRNA gene sequence of a) Streptomyces sp. strain NRC-CHO3 (Query_150927), b) Streptomyces sp. strain NRC-CHO5 (Query_122013), c) Streptomyces sp strain. NRC-CHO6 (Query_60983) and d) Streptomyces sp. strain NRC-CHO10 (Query_44023) with other closely related gene sequences. GenBank accession numbers are mentioned within the parentheses.

\section{Production of cholesterol oxidase in 5L-stirred tank bioreactor}

Microbial production processes for valuable industrial enzymes are generally performed using stirred tank vessels. The homogeneity of growth environment in bioreactors allows better and adequate growth because of homogeneous distribution of oxygen and nutrients. Furthermore, bioreactors avoid the presence of measurable differences in hydrostatic pressures inside cultivation vessels. Additionally, fluid and viscosity characteristics of culture broths are enhanced, which provides growing cells with more favorable cultivation conditions. These conditions are reflected on the improved oxygen and nutrient assimilation rates, when compared to shake-flask cultivations. Accordingly, $\mathrm{CHO}$ production was performed in 5L-BioFlo 310 bench top bioreactor (working volume of $3 \mathrm{~L}$ ), where the final optimized cultivation medium and the most potent producer isolate were used. It can be seen that cells grown in bioreactor had enhanced growth and production kinetics (Fig. 5). Up to $40 \mathrm{~h}$, cellular growth followed normal exponential growth pattern, where cellular growth rate averaged about $0.18 \mathrm{~g} / \mathrm{L} / \mathrm{h}$. Accordingly, cells reached their maximal $(7.9 \mathrm{~g} / \mathrm{L})$ at $46 \mathrm{~h}$. Afterwards, cellular growth was more or less stable, with a decreased in growth rate $(0.01 \mathrm{~g} / \mathrm{L} / \mathrm{h})$. Additionally, it can be seen that cells consumed the provided oxygen at their highest rates during the exponential growth phase. Up to $40 \mathrm{~h}$, oxygen consumption rate reached $2.11 \% / \mathrm{h}$. When cellular growth was stabilized, oxygen consumption continued for another $40 \mathrm{~h}$. Accordingly, oxygen consumption decreased step-wisely and ceased by $80 \mathrm{~h}$, where the cultivation was saturated by oxygen. For $\mathrm{CHO}$ production, cells started to produce $\mathrm{CHO}$ during the exponential growth phase, meaning that enzyme production is growth associated. This was moreover confirmed when enzyme production started to become constant by entering the stationary growth phase. The $\mathrm{CHO}$ production rate in bioreactor averaged about $2.14 \mathrm{U} / \mathrm{mL} / \mathrm{h}$ during first $46 \mathrm{~h}$, and the maximum $\mathrm{CHO}$ production reached $29.4 \mathrm{U} / \mathrm{mL}$ at $52 \mathrm{~h}$. This concentration was higher by $4 \%$ and earlier by 44 hours than that obtained during shake-flask cultivation $(23.7 \mathrm{U} / \mathrm{mL})$ at $96 \mathrm{~h}$. Afterwards, enzyme production was almost stable until cultivation was ended. Concomitantly, $\mathrm{CHO}$ specific yield coefficient $\left(\mathrm{Y}_{\mathrm{P} / \mathrm{X}}\right)$ recorded its maximum (4024.69 U/g cells) at $58 \mathrm{~h}$, and then ranged from 3551.4 to $3795.2 \mathrm{U} /$ $\mathrm{g}$ cells by the end of cultivation. In our findings, results revealed that a scale-up process greatly enhances $\mathrm{CHO}$ production, when compared to shake-flask level. Similarly, Srivastava et al. (2018a) has revealed 4.75 -fold increase in CHO production from Streptomyces rimosus using $3 \mathrm{~L}$ bioreactor as compared to shakeflask production. The larger scale cell cultivations were carried out previously by Prasad et al. (2014) used stirred tank bioreactors to produce industrial enzymes. Also, Felse and Panda (2000) produced chitinase by Trichoderma harzianum in stirred tank bioreactor. On the other hand, Ueda et al. (2011a) produced FR901379-acylase by Streptomyces sp. 6907 and Rahulan et al. (2011) produced leucine amino peptidase by Str. gedanensis in a large-scale bioreactor whereas the production of peroxidase by Streptomyces sp. strain BSII\#1 was reported by Musengi et al. (2014).

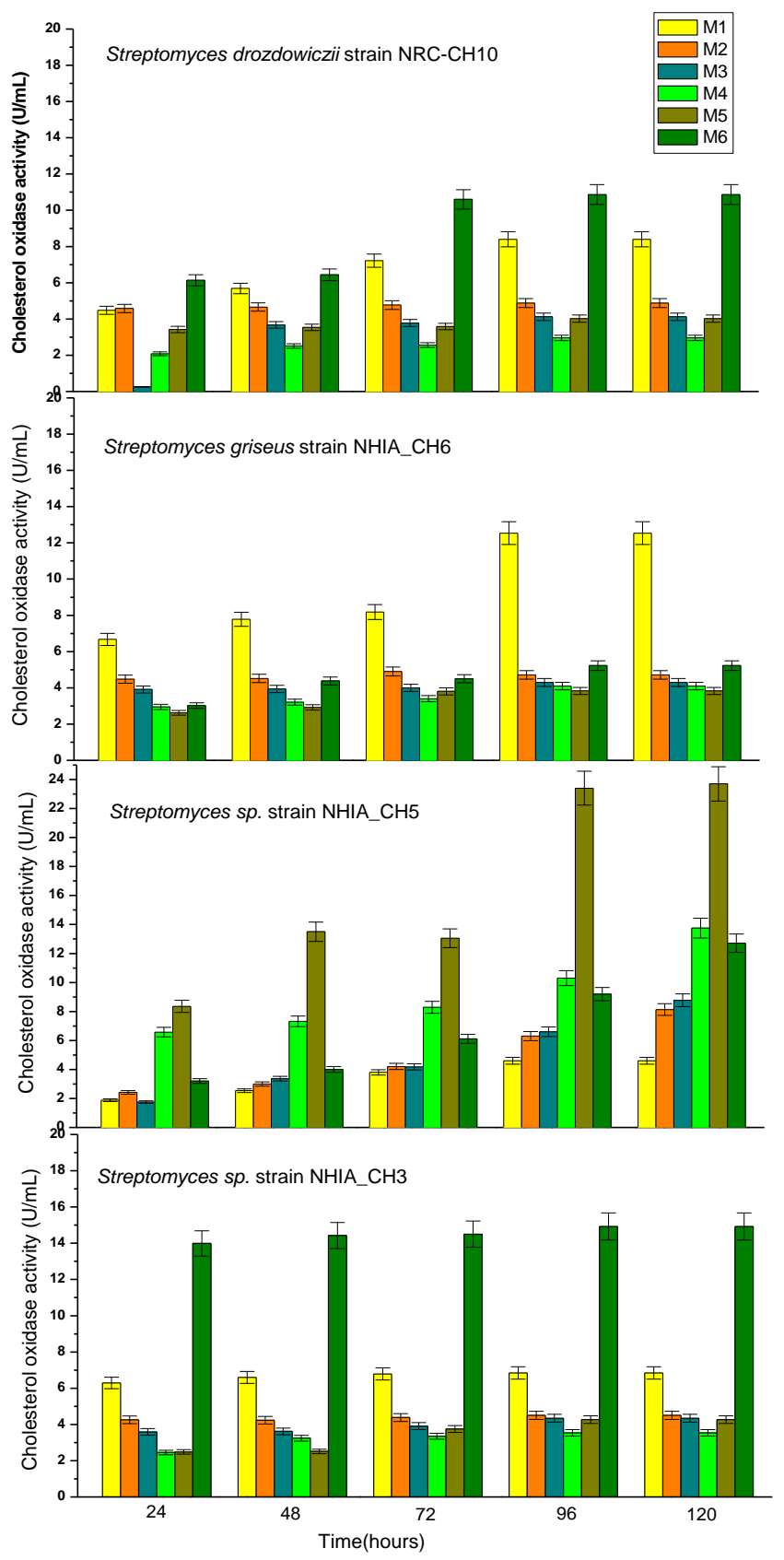

Figure $4 \mathrm{CHO}$ production profile for Streptomyces isolates in different media containing cholesterol as inducer at shake flask level in submerged cultures 


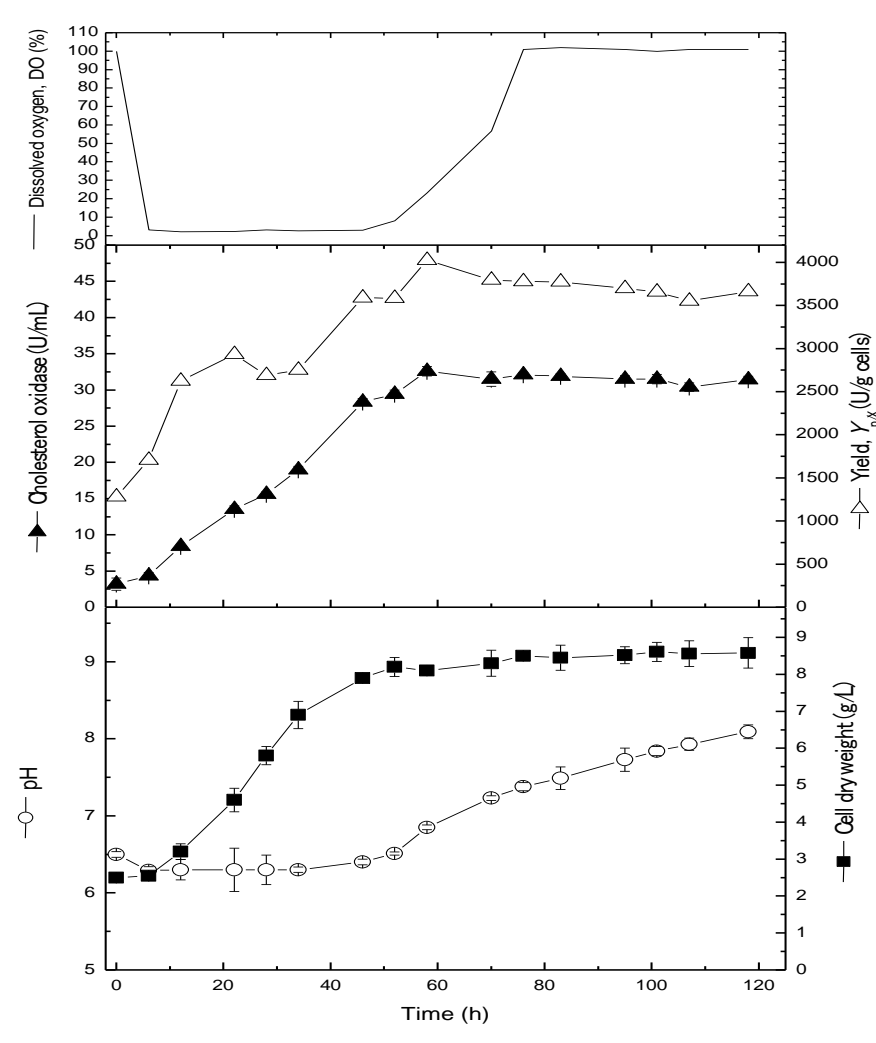

Figure 5 Kinetics of cells growth and $\mathrm{CHO}$ production by Streptomyces sp. strain NHIA_CH5 in 5L stirred tank bioreactor

\section{CONCLUSION}

In the present study, prominent isolates of Streptomyces for the biosynthesis of $\mathrm{CHO}$ enzyme were isolated from soil samples of Egypt. They were identified based on colony characters, pigmentation profile, physiological, biochemical and microscopic features and were characterized as Streptomyces based on conventional taxonomy and confirmed by molecular identification. The production of $\mathrm{CHO}$ enzyme by Streptomyces isolates on different media was varied depending on the medium composition and the isolate potential. The most powerful isolate with the suitable medium for maximum production were chosen for the scale-up study in a 5L laboratory-scale bioreactor. Results showed that the CHO enzyme production was enhanced by $4 \%$ activity reaching up to $29.4 \mathrm{U} / \mathrm{mL}$ at $52 \mathrm{~h}$ in large scale production as compared to the shake flask level with the maximum activity of $23.7 \mathrm{U} / \mathrm{mL}$ at $96 \mathrm{~h}$ incubation time. In the present investigation, Streptomyces sp. strain NHIA_CH5 is favored with the capability to degrade cholesterol and represented a good source for $\mathrm{CHO}$ that can be exploited for potential biomedical, environmental, and industrial applications.

Acknowledgments: The authors are grateful to the authorities of National Research Centre, Dokki, Giza, Egypt, for providing laboratory facilities and funding this work (project No. 11090302) to carry out this study. The authors are very grateful to Prof. Mohamed Abdel-Fattah Farid the consultant of the project for his support and scientific guidance during the project work in our laboratory.

\section{REFERENCES}

Allain, C.C., Poon, L.S., Chan, C.S.G., Richmond, W. \& Fu, P.C. (1974). Enzymatic determination of total serum cholesterol. Clinical Chemistry, 20, 470475. https://doi.org/10.1093/clinchem/20.4.470

K., Nagasawa, M., Bae, M. \& Tamura, G. (1969). Microbial transformation of sterols. Part I. Decomposition of cholesterol by microorganisms. Agricultural and biological chemistry, 33, 1636-1643. https://doi.org/10.1271/bbb1961.33.1636 Awad, H. \& Germoush, M. (2017). Molecular and morphological identification of Streptomyces sp. NRC-88 nova species as $\beta$ - lactamase inhibitor for pharmaceutical application. Asian Journal of Pharmaceutical and Clinical Research, 10(10), 376-383.https://doi.org/10.22159/ajpcr.2017.v10i10.20201 Boudemagh, A., Kitouni, M., Boughachiche, F., Hamdiken, H., Oulmi, L., Reghioua, S., Zerizer, H., Couble, A., Mouniee, D., Boulahrouf, A. \& Boiron, P. (2005). Isolation and molecular identification of actinomycetes microflora of some saharian soils of south east Algeria (Biskra, El-Oued and Ourgla) study of antifungal activity of isolated strains. Journal of Medical Mycology, 15, 3944.https://doi.org/10.1016/j.mycmed.2004.12.004

Chauhan, A. K., Survase, S. A., Kishenkumar, J. \& Annapure, U. S. (2009). Medium optimization by orthogonal array and response surface methodology for cholesterol oxidase production by Streptomyces lavendulae NCIM 2499. Journal of General and Applied

Microbiology, $\quad 55$

$171-180$

https://doi.org/10.2323/jgam.55.171

Collins, T., Azevedo-Silva, J., Costa, A., Branca, F., Machado, R. \& Casal, M. (2013). Batch production of a silk-elastin-like protein in E. coli BL21 (DE3): key parameters for optimization. Microbial Cell Factories, 12, 21. https://doi.org/10.1186/1475-2859-12-21

Cross, T. (1989).

Growth and examination of actinomycetes some guidelines, In: Williams ST, Sharpe ME, Holt JG (Eds). Bergey's manual 4th ed. Baltimore: Williams and Wilkins. pp. 2340-2343.

Elsayed, E. A., \& Ahmed Abdelwahed, N. (2020). Medium Optimization by Response Surface Methodology for Improved Cholesterol Oxidase

Production by a Newly Isolated Streptomyces rochei NAM-19 Strain. BioMed research international, 2020, 1870807. https://doi.org/10.1155/2020/1870807 Fazaeli, A., Golestani, A., Lakzaei, M., Varaei, S.S., \& Aminian, M. (2018). Expression optimization of recombinant cholesterol oxidase in Escherichia coli and its purification and characterization. Applied Microbiology Biotechnology express, 8,183-192. https://doi.org/ 10.1186/s13568-018-0711-3.

Ismail, G. S., Nayera, A.M.A., Hassan, M.A., Magdy, A. S., Kamal, Y.I.E. \& Emam, A. A. (2017).Enhancement of clavulanic acid production by Streptomyces sp. MU-NRC77 via mutation and medium optimization. Tropical Journal of Pharmaceutical Research, 16 (1), 31- 42. https://doi.org/10.4314/tjpr.v16i1.5 Kajiya, Y., Tsuda, R. \& Yoneyama, H. (1991). Conferment of cholesterol sensitivity on polypyrrole films by immobilization of cholesterol oxidase and ferrocenecarboxylate ions. Journal of Electroanalytical Chemistry and Interfacial Electrochemistry, 301, 155-164. https://doi.org/10.1016/0022-0728(91)85466-3

Lee, S. Y., Rhee, H. I., Tae, W. C., Shin, J. C. \& Park, B. K.(1989). Purification and characterization of cholesterol oxidase from

Pseudomonas sp. and taxonomic study of the strain. Applied Microbiology and Biotechnology, 31, 542-546. https://doi.org/10.1007/BF00270791 Lowry, O.H., Rosebrough, N.J., Farr, A.L. \& Randall, R.J. (1951). Protein measurement with the Folin phenol reagent. Journal of Biological Chemistry, 193, 265-275.

Maleki, H., Dehnad, A., Hanifian, S., \& Khani, S. (2013). Isolation and Molecular Identification of Streptomyces spp. with Antibacterial Activity from Northwest of Iran. BioImpacts: BI, 3, 129-134. https://doi.org/10.5681/bi.2013.017

Musengi, A., Khan, N., Le Roes-Hill, M., Pletschke, B. \& Burton, S. (2014), Increasing the scale of peroxidase production by Streptomyces strain BSII\#1.. Journal of Applied Microbiology, 116, 554-562. https://doi.org/10.1111/jam.12380

Nagasawa, M., Bae, M., Tamura, G. \& Arima, K. (1969). Microbial transformation of steroids. Part II. Cleavage of sterols side chains by microorganisms. Agricultural and biological chemistry, 33, 1644-1650. https://doi.org/10.1080/00021369.1969.10859516

Niwas, R., Singh, V., Singh, R., Tripathi, D. \& Tripath, C.K.M. (2013). Production , purification and characterization of cholesterol oxidase

from a newly isolated Streptomyces sp. World Journal of Microbiology and Biotechnology, 29, 2077-2085.

https://doi.org/10.1007/s11274-013-1371-8

Prasad, R., Abraham, Tk \& Nair, A. J. (2014). Scale up of production in a bioreactor of a halotolerant protease from moderately halophilic

Bacillus sp. isolated from soil. Brazilian Archives of Biology and Technology, 57, 448-455. https://doi.org/10.1590/S1516-89132014005000014

Rahulan, R., Dhar, K.S., Nampoothiri, K.M., Pandey, A. (2011). Production of leucine amino peptidase in lab scale bioreactors using

Streptomyces gedanensis. Bioresource Technology, 102, 8171-8178. https://doi.org/10.1016/j.biortech.2011.06.037

Richmond, W. (1973). Preparation and properties of a cholesterol oxidase from Nocardia sp. and its application to the enzymatic assay of

cholesterol in serum. Clinical Chemistry,

https://doi.org/10.1093/clinchem/19.12.1350

Rintala, H., Nevalainen, A., Rönkä, E. \& Suutari, M. (2001). PCR primers targeting the 16S rRNA gene for the specific detection of

Streptomycetes. Molecular and Cellular Probes, 15, 337-

347. https://doi.org/10.1006/mcpr.2001.0379

Salim, F.M., Sharmili, S.A., Anbumalarmathi, J. \& Umamaheswari, K. (2017). Isolation, Molecular Characterization and Identification of

Antibiotic Producing Actinomycetes from Soil Samples. Journal of Applied Pharmaceutical Science ,7, 069-075.

https://doi.org/10.7324/JAPS.2017.70909

Saranya, S., Shekinah, S., Rajagopal, T., Vijayakumar, J. \& Ponmanickam, P. (2014). Isolation and characterization of cholesterol degrading

bacteria from soap and vegetable oil industrial waste. Indian Journal of Biotechnology, 13, 508-513.

Shepherd, M.D., Kharel, M.K., Bosserman, M.A. \& Rohr, J. (2010). Laboratory maintenance of Streptomyces species. Current Protocols in

18, 1-8. https://doi.org/10.1002/9780471729259.mc10e01s18 
Shirling, E.B. \& Gottlieb, D. (1966). Methods for characterization of Streptomyces species. International Journal of Systematic Bacteriology,

16, 313-340. https://doi.org/10.1099/00207713-16-3-313

Singh, V., Haque, S., Singh, H., Verma, J., Vibha, K., Singh, R., Jawed, A., \&

Tripathi, C. K. (2016). Isolation, Screening, and Identification of Novel Isolates of Actinomycetes from India for Antimicrobial Applications. Frontiers in microbiology, 7, 1921.https://doi.org/10.3389/fmicb.2016.01921

Singh, V., Haque, S., Niwas, R., Srivastava, A., Pasupuleti, M., \& Tripathi, C. K. (2017). Strategies for Fermentation Medium Optimization: An In-Depth $\begin{array}{llll}\text { Review. Frontiers in microbiology, } & 7, & 2087 .\end{array}$ https://doi.org/10.3389/fmicb.2016.02087 Srivastava, A. Verma, J., Singh, H., Niwas, R., Kumari, V., Gangwar, M., Khan, A., Tripathi, C.M., \& Singh, V. (2018). Screening of biologically active microbial strains having therapeutic applications. Indian Journal of Experimental Biology, 56, 244-251. Srivastava, A., Niwas, R., Singh, V., Khan, A., \& Tripathi, C.K.M. (2015). Microbial cholesterol oxidases. International Journal of Innovation Science and Research, 3, 1-11. https://doi.org/10.1021/ ja01094a041 Srivastava, A., Singh, V. \& Tripathi, C.K.M. (2018a). Scale up and optimization of cholesterol oxidase production from Streptomyces rimosus

MTCC 10792 in a 3-L bioreactor. Environmental and Sustainability, 1, 99 107.https://doi.org/10.1007/s42398-018-0008-0

Tabatabaei, M., Malekzadeh, F., Zarrini, G.H., Faramarzi, M.A. \& Kamranpour, N. (2001). Production of cholesterol oxidase by a newly isolated Rhodococcus sp. World Journal of Microbiology and Biotechnology, 17, 731737. https://doi.org/10.1023/A:1012993532686

Taddei, A., Jose, R.M., Marquez-Vilchez, E. \& Castelli, C. (2006). Isolation and identification of Streptomyces spp. From Venezuelan soils: Morphological and biochemical studies. Microbial Research, 161, 222-231. https://doi.org/10.1016/j.micres.2005.08.004

Thiry, M. \& Cingolani, D. (2002). Optimizing scale-up fermentation processes. Trends in Biotechnology, 20,103-105. https://doi.org/10.1016/S01677799(02)01913-3

Ueda, S., Kinoshita, M., Tanaka, F., Tsuboi ,M., Shimizu, S., Oohata, N., Hino, M., Yamada, M., Isogai, Y. \& Hashimoto, S. (2011a). Strain selection and scale-up fermentation for FR901379 acylase production by Streptomyces sp. no 6907. Journal of Bioscience and Bioengineering, $112, \quad 409 \quad-\quad 414$ https://doi.org/10.1016/j.jbiosc.2011.06.002.

Varma, R. \& Nene, S. (2003). Biosynthesis of cholesterol oxidase by Streptomyces lavendulae NCIM 2421. Enzyme and Microbial Technology,33, 286-291. https://doi.org/10.1016/S0141-0229(03)00126-1

Whitman, W.B., Coleman, D.C., Wiebe \& W.J. (1998). Prokaryotes: The unseen majority. Proc. Nat. Acad. Sci. USA. 95:6578-6583 https://doi.org/10.1073/pnas.95.12.6578

Yamada, K., Koroleva, A., Laughlin, M., Oksanen, N., Akhgari, A., Safronova V., Yakovleva, E. Kolodyaznaya, V., Buldakova, T. \& Mikko Metsä, K. (2019). Characterization and overproduction ofcell-associated cholesterol oxidase ChoD from Streptomyces lavendulae YAKB-15. Scientific Reports, 9, 11850. https://doi.org/10.1038/s41598-019-48132-1

Yazdi, M. T., Zahraei, M., Aghaepour, K. \& Kumaranpour, N. (2001). Purification and partial characterization of cholesterol oxidase from

Streptomyces fradiae. Enzyme and Microbial Technology, 18, 410-414 https://doi.org/10.1016/S0141-0229(00)00337-9

Yehia, H.M., Hassanein, W.A. \& Ibraheim, S.M. (2015). Purification and characterization of the extracellular cholesterol oxidase enzyme from Enterococcus hirae . BMC Microbiol, 15, 178. https://doi.org/10.1186/s12866015-0517-2 